Old Dominion University

ODU Digital Commons

Community \& Environmental Health Faculty

Publications

Community \& Environmental Health

2020

\title{
Risk Factors for Workplace Encounters with Weapons by Hospital Employees
}

James Blando

Old Dominion University, jblando@odu.edu

Chalsie Paul

Old Dominion University

Mariana Szklo-Coxe

Old Dominion University, mszklo@odu.edu

Follow this and additional works at: https://digitalcommons.odu.edu/commhealth_fac_pubs

Part of the Health and Medical Administration Commons, Organizational Behavior and Theory Commons, and the Public Health Commons

Original Publication Citation

Blando, J., Paul, C., \& Szklo-Coxe, M. (2020). Risk factors for workplace encounters with weapons by hospital employees. Public Health in Practice, 2, 1-4, Article 100105. https://doi.org/10.1016/

j.puhip.2021.100105

This Article is brought to you for free and open access by the Community \& Environmental Health at ODU Digital Commons. It has been accepted for inclusion in Community \& Environmental Health Faculty Publications by an authorized administrator of ODU Digital Commons. For more information, please contact digitalcommons@odu.edu. 
Original Research

\title{
Risk factors for workplace encounters with weapons by hospital employees
}

\author{
James D. Blando ", Chalsie Paul, Mariana Szklo-Coxe \\ Old Dominion University, College of Health Sciences, School of Community and Environmental Health, Norfolk, VA, USA
}

\section{A R T I C L E I N F O}

\section{Keywords:}

Workplace violence

Weapons

Injury

Security

Confiscation

Prevention

\begin{abstract}
A B S T R A C T
Objective: The specific aim of this study was to determine which risk factors were associated with frequent weapons confiscation in a healthcare facility. This study investigated the hypothesis that hospital-related factors impact the frequency of weapons confiscation.

Study design: Cross-sectional.

Methods: A cross-sectional survey was administered on-line to hospital security directors and assessed the associations of organizational factors with the frequency of weapons confiscation.

Results: It was found that hospitals with metal detectors were more than 5 times as likely to frequently confiscate weapons, suggesting this intervention is effective. It was also found that hospitals with psychiatric units were more likely to have frequent confiscation of weapons, likely due to the standard procedure of searching patients before admission to the psychiatric unit.

Conclusion: This data suggests that searching patients and using metal detectors are important tools in the prevention of weapons entering a healthcare setting.
\end{abstract}

\section{Introduction}

It is well known that healthcare workers experience very high rates of injuries from workplace violence. For example, the Bureau of Labor statistics found in 2018 that psychiatric and substance abuse hospitals had 62 times the rate of intentional injury from workplace violence compared to the rate of all industries combined. The prevention and control of weapons in a hospital environment are crucial to preventing violence and to assuring a safe, healthy, and effective healthcare environment. Violence and the fear of violence impact healthcare employee retention [1], medical mistakes [2], and patient satisfaction [3,4]. The present study aimed to elucidate organizational factors related to weapons confiscation in hospitals. This study examines weapons confiscation and its associations with metal detector presence, and other factors including hospital settings (urban/rural settings, region where hospital is located), type of hospital, individual hospital departments where incidents may have occurred (emergency department or other), and hospital policies concerning staff being armed.

Weapons are commonly encountered by healthcare providers, especially in a hospital environment. Cunningham et al. [5] used a cross-sectional survey of adolescents visiting an urban emergency department and found that $20 \%$ of the adolescents surveyed reported carrying a knife or razor blade at some point over the last year, $7 \%$ reported carrying a gun, and $6 \%$ reported pulling a knife or gun on someone over the last year. Males were more likely to carry a gun than females, but both males and females were equally likely to carry cutting weapons, such as razor blades, and to threaten someone by displaying the weapon [5]. Smalley et al. [6] conducted a 15 month-long survey of weapons confiscated by security at eight emergency department entry points in a large urban healthcare system representing 346,323 emergency department hospital visits; they found that roughly $3 \%$ of the ED visits (10, 691 weapons) resulted in a weapon being confiscated. Of these confiscated weapons, approximately $56 \%$ were knives, $21 \%$ were mace, $5 \%$ were razor blades, $6 \%$ were box cutters, $5 \%$ were scissors, $5 \%$ were tools, $2 \%$ were TASERs, $0.5 \%$ were screw-drivers, and $0.3 \%$ were firearms [6]. Smalley et al. [6] also found that trauma centers and behavioral health units represented the highest rate of confiscations and that this rate was unrelated to race, ethnicity, or gender of the population seeking care.

Rankins \& Hendey [7] and Irvin \& Habas [8] studied the impact of a hospital security system to intercept and remove weapons from patients coming to a hospital emergency department. They found that the patient volume-adjusted rate of weapons confiscation more than doubled after implementation of a screening program. While the number of assaults

\footnotetext{
* Corresponding author. Old Dominion University, College of Health Sciences, School of Community and Environmental Health, 4608 Hampton Blvd., Norfolk, VA, 23529, USA.

E-mail address: jblando@odu.edu (J.D. Blando).
} 
occurring in patient care areas remained the same after implementation, the number of assaults involving weapons decreased. The assaults that occurred were thus carried out without a weapon because the weapon was confiscated during the initial patient screening. Almost half of the weapons confiscated were from patients who had bypassed walk-through screening because they arrived on a stretcher [7]. The use of metal detectors is often thought to promote a negative image and considered poor customer friendliness [9]. This may result in resistance to their deployment and use by hospital administrators [9]. However, several studies have found that patients, visitors, and staff all support the use of metal detectors and in-fact, the use of metal detectors has often been viewed as an enhanced and desirable customer service feature by the majority of those surveyed [9-11].

Policies and decisions made regarding screening for weapons and the subsequent disposition of those weapons discovered in a healthcare facility requires significant deliberation and an attempt to account for the multiple complex factors that affect the potential risks. The present survey-based study tested the hypothesis that specific hospital-related factors are associated with increased risk of frequent confiscation of weapons.

\section{Methods}

This study utilized a validated anonymous on-line cross-sectional survey to collect data from security professionals who were members of the International Association of Healthcare Security and Safety (IAHSS; http://www.iahss.org/) and working in the United States. The typical member of this organization is a security professional, often the director of security, at a hospital or within a hospital system. This survey was broad in scope and asked questions that covered a wide variety of issues related to firearms and other weapons encountered in a healthcare setting. The survey notice was sent out to over 2200 IAHSS members on three occasions over a 6 month period of time with approximately 2 months between each contact. The survey notice was embedded in the IAHSS monthly electronic E-mailed newsletter. Details of survey design, validation, and sampling can be found in Blando et al. [12]. This analysis was confined only to those survey respondents who worked for healthcare facilities in the United States of America.

In this assessment, factors that may contribute to the frequency of weapons confiscation in a healthcare facility were assessed. The dependent variable was weapons confiscation. Weapons included any device where the intent is that it could be used to injure an individual. Examples of commonly encountered items include guns, knives, shanks, hammers, clubs, scissors, screw drivers, and razor blades.

An analysis of the self-reported frequency of weapon confiscation by the survey respondents was analyzed in connection with potential explanatory predictors using Chi-Square tests and logistic regression, both unadjusted and adjusted.

\subsection{Predictors/covariates}

Predictor/covariate variables examined included the following: a) perception of their facility to be at high risk of violence (yes vs. no); b) whether the survey respondent reported their facility decision to arm guards was a response to violence in the community (yes vs. no); c) whether the state where they work has open-carry firearm laws (yes vs. no), d) whether the hospital where they work currently use metal detectors (yes vs. no); e) the type of facility, including whether their facilities were trauma hospitals (yes vs. no) or psychiatric hospitals (yes vs. no); f) the type of community, categorized as rural, suburban, or urban; g) the number of firearms by state registered with the Federal Bureau of Alcohol, Tobacco, Firearms and Explosives (ATF) (above national median value or below); h) the state violent crime rate (above national median value or below), i) whether the state where they work requires mandatory background checks to purchase a firearm (yes vs. no), $j$ ) the size of their facility based on the number of inpatient hospital beds, $k$ ) and the
Giffords Law Center to prevent gun violence scorecard firearms law grade given to the state where the survey respondent works (grades A \& B versus grades $\mathrm{C}-\mathrm{F}$ ) [9].

\subsection{Outcome}

The outcome measure was the response to the survey question about the frequency of security confiscating weapons with four multiple choice options (daily, weekly, monthly, or less than monthly). The confiscation frequency was dichotomized by collapsing responses for daily and weekly into the "frequent" category, and monthly and less than monthly into the "non-frequent" category.

\subsection{Analysis}

Continuous predictor variables were dichotomized by coding those above the median as "high" and those below as "low" based on the following median values: the median statewide violent crime rate was 377 incidents per 100,000 people, the median registered firearms per capita was 0.0035 per person, and the median number of inpatient hospital beds was 300. Two-by-two tables of the confiscation frequency category by each listed categorical predictor or covariate were examined, and each distribution of counts in the tables was evaluated for statistical significance using a Chi-square or Fisher's Exact test. A P value of $\leq 0.05$ was considered statistically significant. A univariate logistic regression [13] was also run to determine the univariate unadjusted odds ratio of the predictors with regard to the outcome. Potential explanatory variables that were statistically significant at $\mathrm{p} \leq 0.05$ where then included in a multivariate logistic regression model [10]. Odds ratios and maximum likelihood estimates from the logistic regression were estimated according to the logistic procedure run in SAS v9.3.

The adjusted multivariate logistic regression model [13] included the five predictor/covariate variables that were statistically significant at $p$ $\leq 0.05$ in the univariate analysis (see Table 1). All five variables considered were assessed for multicollinearity by computing variance inflation factors (VIF) and assessed for interactions using SAS v9.3. The final model included these five predictive factors as they were either significantly associated with the outcome and/or potential confounding factors.

\section{Results}

After data cleaning, removal of any duplicates, and removal of those survey respondents who did not work in the United States or who worked in locations that could not be determined, a total of 77 survey respondents were included in analyses. The unadjusted odds ratio and $\mathrm{P}$ values for each univariate analysis are listed in Table 1 , where the outcome modeled was frequent weapons confiscation (daily or weekly) versus the reference of non-frequent weapons confiscation (monthly or less-than-monthly). Of the 12 potential predictor variables, five had statistically significant (at $\mathrm{p} \leq 0.05$ ) associations with frequent weapons confiscation, while the other seven variables were not statistically significantly related to frequent confiscation. Overall, the variables that were statistically significant at $\mathrm{p} \leq 0.05$ included those specific to the facility where the survey respondent worked, and, generally, those that were not statistically significant were more general statewide proxy descriptors of weapons prevalence and risk.

The five predictors considered for the multivariate model were not found to have any significant interactions, where $p$ values for the interaction terms ranged between 0.62 and 0.98 . These five predictors all had variance inflation factors less than 2.5 , with a range from 1.09 to 1.26 . This suggested that interactions and multicollinearity were not significant among these five predictors [14]. As a result, the multivariate logistic regression included the five predictor variables found to be statistically significant at $\mathrm{p} \leq 0.05$ in the univariate analyses. The outcome for the logistic regression model was frequent confiscation of 
Table 1

Unadjusted Associations of Hospital, Policy, and Legal Factors with Frequent (daily or weekly) Weapons Confiscation in Hospitals.

\begin{tabular}{|c|c|c|c|c|}
\hline $\begin{array}{l}\text { Potential Predictors } \\
\text { of frequent weapons } \\
\text { confiscation }\end{array}$ & Frequency & $\begin{array}{l}\text { Unadjusted } \\
\text { Odds Ratio }\end{array}$ & $\begin{array}{l}95 \% \\
\text { Confidence } \\
\text { Interval }\end{array}$ & $\begin{array}{l}\mathrm{P} \text { - } \\
\text { value }\end{array}$ \\
\hline $\begin{array}{l}\text { *a) Health care } \\
\text { facility perceived } \\
\text { to be at high risk of } \\
\text { violence }(\mathrm{n}=76)\end{array}$ & $\begin{array}{l}\text { Yes }=62 \\
\text { No }(\text { ref })=14\end{array}$ & 12.99 & $1.60-105.50$ & 0.016 \\
\hline $\begin{array}{l}\text { *b) Decision to arm } \\
\text { guards was a } \\
\text { response to } \\
\text { violence in the } \\
\text { community ( } \mathrm{n}= \\
66 \text { ) }\end{array}$ & $\begin{array}{l}\text { Yes }=23 \\
\text { No (ref) }=43\end{array}$ & 4.33 & $1.47-12.70$ & 0.0077 \\
\hline $\begin{array}{l}\text { c) State allows open- } \\
\text { carry of firearms (n } \\
=76)\end{array}$ & $\begin{array}{l}\text { Yes }=37 \\
\text { No (ref) }=39\end{array}$ & 1.095 & $0.44-2.72$ & 0.85 \\
\hline $\begin{array}{l}\text { *d) Use of metal } \\
\text { detectors }(n=75)\end{array}$ & $\begin{array}{l}\text { Yes }=37 \\
\text { No }=38\end{array}$ & 2.89 & $1.11-7.49$ & 0.029 \\
\hline $\begin{array}{l}\text { e) Trauma hospital } \\
(\mathrm{n}=76)\end{array}$ & $\begin{array}{l}\text { Yes }=43 \\
\text { No }=33\end{array}$ & 1.52 & $0.60-3.85$ & 0.38 \\
\hline $\begin{array}{l}\text { *e) Psychiatric } \\
\text { hospital } \\
(n=76)\end{array}$ & $\begin{array}{l}\text { Yes }=38 \\
\text { No }=38\end{array}$ & 4.94 & $1.83-13.31$ & 0.0016 \\
\hline $\begin{array}{l}\text { *f) The type of } \\
\text { community }(\mathrm{n}= \\
76)\end{array}$ & $\begin{array}{l}\text { Suburban \& } \\
\text { urban }=60 \\
\text { Rural (ref) }= \\
16 \\
\text { Missing =1 }\end{array}$ & 7.00 & $1.46-33.50$ & 0.015 \\
\hline $\begin{array}{l}\text { g) The number of } \\
\text { firearms registered } \\
(\mathrm{n}=76)\end{array}$ & $\begin{array}{l}\text { High }=30 \\
\text { Low }(\text { ref })= \\
46\end{array}$ & 0.87 & $0.34-2.21$ & 0.76 \\
\hline $\begin{array}{l}\text { h) Statewide violent } \\
\text { crime rate }(n=76)\end{array}$ & $\begin{array}{l}\text { High }=35 \\
\text { Low (ref) }= \\
41\end{array}$ & 0.85 & $0.34-2.13$ & 0.73 \\
\hline $\begin{array}{l}\text { I) Statewide } \\
\text { mandatory } \\
\text { background checks } \\
\text { for firearm } \\
\text { purchases (( } \mathrm{n}= \\
73)\end{array}$ & $\begin{array}{l}\text { Yes }=69 \\
\text { No (ref) }=4\end{array}$ & 0.23 & $0.023-2.30$ & 0.21 \\
\hline $\begin{array}{l}\mathrm{J}) \text { The size of the } \\
\text { facility based on } \\
\text { the number of } \\
\text { inpatient hospital } \\
\text { beds }(\mathrm{n}=76)\end{array}$ & $\begin{array}{l}\text { High }=31 \\
\text { Low }=45\end{array}$ & 0.99 & $0.39-2.50$ & 0.98 \\
\hline $\begin{array}{l}\text { k) firearms law grade } \\
\text { given to the state } \\
\text { where the survey } \\
\text { respondent works } \\
(\mathrm{n}=76)\end{array}$ & $\begin{array}{l}\text { A\&B (higher } \\
\text { grades) }=24 \\
C, D, F \\
\text { (lower } \\
\text { grades) (ref) } \\
=52\end{array}$ & 0.53 & $0.095-3.00$ & 0.48 \\
\hline
\end{tabular}

* statistically significant.

weapons at the survey respondents' facilities, meaning a daily or weekly occurrence at their facility. The results in Table 2 indicate that, of the five predictors significant in the univariate analysis, only two remained significant in the multivariate model.

However, given the likely confounding effect of these variables, all five variables were maintained in the model. Relative to the unadjusted odds ratios (Table 1), the adjusted odds ratio (Table 2) for the association of the use of metal detectors with frequent confiscation of weapons was almost doubled and the adjusted odds ratio for psychiatric units with respect to frequent confiscation of weapons was slightly decreased. Perceived high risk, decision to arm guards, and community type were associated with decreased odds with regard to the frequent confiscation of weapons in the adjusted model.

\section{Discussion}

The presence, handling, and response to weapons in a healthcare facility are important health and safety issues for employees, patients,
Table 2

Adjusted Odds Ratios from Multivariate Logistic Regression for Frequent (daily or weekly) Weapons Confiscation in Hospitals.

\begin{tabular}{|c|c|c|}
\hline Predictor & $\begin{array}{l}\text { Adjusted Odds Ratio (95\% } \\
\text { Confidence Interval) }\end{array}$ & $\begin{array}{l}\text { P- } \\
\text { value }\end{array}$ \\
\hline $\begin{array}{l}\text { Health care facility perceived to be at high } \\
\text { risk of violence (yes vs no; where no is the } \\
\text { reference group) }\end{array}$ & $7.44(0.62-88.78)$ & 0.11 \\
\hline $\begin{array}{l}\text { Decision to arm guards was a response to } \\
\text { violence in the community (yes vs. no; } \\
\text { where no is the reference group) }\end{array}$ & $2.78(0.71-10.85)$ & 0.14 \\
\hline $\begin{array}{l}\text { * Use of metal detectors (yes vs. no; where } \\
\text { no is the reference group) }\end{array}$ & $5.02(1.37-18.50)$ & 0.015 \\
\hline $\begin{array}{l}\text { * Psychiatric hospital (yes vs. no; where no } \\
\text { is the reference group) }\end{array}$ & $3.91(1.04-14.78)$ & 0.044 \\
\hline $\begin{array}{l}\text { Type of community (suburban and urban vs. } \\
\text { rural; where rural is the reference group) }\end{array}$ & $5.14(0.50-52.65)$ & 0.17 \\
\hline
\end{tabular}

and visitors. Understanding the factors associated with weapons confiscation by security is important to the design of interventions to control this hazard and to the evaluation of the effectiveness of interventions.

Most of the assessed geographically-related factors and some of the hospital-related factors were not statistically significant in the chi-square and univariate logistic regression analysis (Table 1). There are likely a number of factors that may be responsible in-total or in-part. For example, the proxies used for geographically-related factors may not be a good predictor of weapons confiscation because there are multiple factors that may impact whether a weapon is discovered and subsequently confiscated. Only about half of the respondents in this survey reported using metal detectors [12], and it is known that metal detectors increase detection frequency $[7,8]$. Therefore, it is possible that, even if community crime predictors were associated with more weapons being brought to the healthcare facility, they may not be efficiently detected at facilities without metal detectors.

The results presented in Table 1 also demonstrate that the statewide policies and laws evaluated were also not significantly associated with the self-reported confiscation rate. States allowing open carry of firearms, requiring background checks for the purchase of firearms, and the Gifford Law Center firearms law grade [15] were not associated with the confiscation rate likely because these policies or laws are focused only on guns and neglects other weapons. It has been shown that edged weapons are much more frequently encountered in a hospital environment compared to firearms [6]. The confiscation question on the survey referred to all weapons while these statewide policies are only focused on guns. Similarly, hospital factors such as having a trauma center and the facility size measured by total in-patient bed number were also not significant in the univariate analysis presented in Table 1. Larger hospitals with more patients and visitors, and hence theoretically a higher probability of encountering a weapon, was not associated with higher weapons confiscation rates and this further underscores the complexity of the relationship between various factors and weapons confiscation.

The unadjusted odds ratios indicate that the magnitude of the associations for the statistically significant predictors in Table 1 were high. For example, a survey respondent who perceived their facility to be at a high risk of violence was about 13 times as likely to report frequent gun confiscation than a respondent who did not perceive their facility to be at high risk of violence. In fact, the weapons confiscation rate may have influenced their perception of the risk. The decision to arm guards as a response to community violence and the degree of urbanization may also be related to the safety and risk perceptions of the survey respondent. Among the survey respondents who worked at a facility with a psychiatric hospital, $13 \%$ of the respondents worked at rural facilities, $29 \%$ at suburban facilities, and $58 \%$ at urban facilities. It is likely that the survey respondents' perception of a high risk of violence and the decision to arm security as a response to community violence were related to the urban nature of some communities and urban hospitals. In this survey, there 
were a larger number of psychiatric facilities in urban hospitals. Thus, the unadjusted findings showing that the perception of their facility being at a high risk of violence, decision to arm security in response to violence, and the type of community may have been influenced by the much higher prevalence of psychiatric facilities in that group. It is also known that psychiatric units are also more likely to use metal detectors during initial patient screenings before admission. As a result, the five factors significant in Table 1 are therefore likely to be impacted by confounding in the multivariate assessment.

After adjustments, the use of metal detectors by a facility security program and the presence of an inpatient psychiatric unit at the hospital were statistically significantly associated with frequent weapons confiscation in hospitals. The metal detector finding is similar to what other researchers have reported $[7,8]$ and suggests that using a metal detector facilitates the discovery and awareness of weapons entering the healthcare facility. Unlike other areas of the hospital, most inpatient psychiatric units routinely search patients before admission as a matter of standard protocol. Therefore, the association of frequent weapons confiscation with the presence of inpatient psychiatric units may have resulted from the frequent practice of routinely searching patients and their belongings before admission, which may include the use of a metal detector (Levin, 2009). As a result, weapons are more likely to be found in psychiatric units.

The policy and program overview reported by Blando et al. [12] demonstrated that only $48 \%$ of survey respondents reported using metal detectors at their facility. This is likely a missed opportunity to significantly enhance security at many healthcare facilities that choose not to use metal detectors. This survey data suggests that metal detectors are effective at increasing the detection and confiscation of weapons. Some of the barriers reported in the literature suggest that hospital administrators are concerned that the use of metal detectors would be objectionable to patients and visitors and therefore not support the administrator's customer service goals [16]. However, McNamara et al. [9] and Mattox et al. [10] showed that the opposite was true in large urban hospital, and that, in fact, many visitors suggested that the use of metal detectors made them feel more safe and therefore increased the chance that they would return to the hospital if needed rather than choosing another hospital. Our survey data and two prior studies $[9,10]$ highlight the importance of metal detectors, including wands and portable detectors, and the effectiveness with which metal detectors can support weapons identification and removal, thereby enhancing safety in the healthcare facility.

As with many cross-sectional studies, this survey had several limitations including uncertainty as to whether the sample drawn was a true representation of the typical hospital security environment across the entire United States. In addition, the relatively low response rate typical of a voluntary survey may also contribute additional uncertainty regarding the representativeness of the sample. Recall and reporting bias may also be important limitations because many of the analyzed variables, such as weapons confiscation frequency, were self-reported by the survey respondent. Despite these limitations, this study explored an important security issue which is difficult to assess due to lack of access to available data sources.

\section{Conclusion}

Healthcare facilities are at risk of encountering many types of weapons among the patients and visitors to their facility. Our survey strongly suggested that the presence of a psychiatric hospital increased the odds of frequent weapons confiscation by approximately four times compared to facilities without an inpatient psychiatric unit. Our data also suggested that the use of a metal detector increased the likelihood of weapons confiscation by more than five times relative to facilities that do not use metal detectors. Metal detectors are a critical component of any security program at healthcare facilities and can play a crucial role in the mitigation of hazards associated with weapons brought to the facility.

\section{Source of funding}

This project was not funded.

\section{Human studies and subjects}

This study was reviewed and approved by the Old Dominion University Institutional Review Board (protocol \#1040377-3) and complies with US Federal Policy for the Protection of Human Subjects.

\section{Declaration of competing interest}

The authors declare that they have no known competing financial interests or personal relationships that could have appeared to influence the work reported in this paper.

\section{Acknowledgements}

The authors wish to acknowledge the International Association of Healthcare Security and Safety (IAHSS; http://www.iahss.org/) for their support of our study and all the members who completed our survey.

\section{References}

[1] D. Gates, G. Gillespie, P. Succop, Violence against nurses and its impact on stress and productivity, Nurs. Econ. 29 (2) (2011) 59-67.

[2] M. Roche, D. Diers, C. Duffield, C. Catling-Paull, Violence toward nurses, the work environment, and patient outcomes, J. Nurs. Scholarsh. 42 (1) (2010) 13-22.

[3] S. Astrom, S. Karlsson, A. Sandvide, G. Bucht, M. Eisemann, A. Norberg, B.I. Saveman, Staff's experience of and the management of violent incidents in elderly care, Scand. J. Caring Sci. 18 (2004) 410-416.

[4] K. Josefsson, L. Sonde, T.-B.R. Wahlin, Violence in municipal care of older people in Sweden as perceived by registered nurses, J. Clin. Nurs. 16 (5) (2007) 900-910.

[5] R. Cunningham, S. Resko, S. Harrison, M. Zimmerman, R. Stanley, S. Chermack, et al., Screening adolescents in the emergency department for weapon carriage, Acad. Emerg. Med. 17 (2010) 168-176.

[6] C. Smalley, M. O'Neil, R. Engineer, E. Simon, G. Snow, S. Podolsky, Dangerous weapons confiscated after implementation of routine screening across a healthcare system, Am. J. Emerg. Med. 36 (2017) 1497-1520.

[7] R.C. Rankins, G.W. Hendey, Effect of a security system on violent incidents and hidden weapons in the emergency department, Ann. Emerg. Med. 33 (1999) 676-679.

[8] C.B. Irvin, R.C. Habas, Weapon changes over time after initiation of a comprehensive weapon surveillance system, Am. J. Emerg. Med. 17 (3) (1999) 323-324.

[9] R. McNamara, D. Yu, J. Kelly, Public perceptions of safety and metal detectors in an urban emergency department, Am. J. Emerg. Med. 15 (1997) 40-42.

[10] E. Mattox, S. Wright, A. Bracikowski, Metal detectors in the pediatric emergency department: patron attitudes and national prevalence, Pediatr. Emerg. Care 16 (3) (2000) 163-165.

[11] T. Meyer, K. Wrenn, S. Wright, J. Glaser, C. Slovis, Attitudes towards the use of a metal detector in an urban emergency department, Ann. Emerg. Med. 29 (1997) $621-624$.

[12] J.D. Blando, R. Cramer, M. Szklo-Coxe, Hospital security programs and policies related to guns and other weapons, J. Healthc. Manag. 64 (3) (2019) 157-166.

[13] Hosmer, Lemeshow, Applied Logistic Regression, John Wiley Publishers, New York, 1989.

[14] R. Cody, J. Smith, Applied Statistics and the SAS Programming Language, fifth ed., Pearson Prentice Hall, Upper Saddle River, NJ, 2006.

[15] Giffords Law Center, Annual Gun Law Scorecard [Available from: http://lawc enter.giffords.org/scorecard/. (Accessed 14 April 2018).

[16] J.D. Blando, M. Ridenour, D. Hartley, C. Casteel, Barriers to effective implementation of programs for workplace violence prevention in hospitals, Online J Issues Nurs [Internet 20 (1) (2015). 